\title{
HEALTH SECTOR LEADERSHIP TO COMBAT CLIMATE CHANGE
}

\author{
Alexander Thomas, Divya Alexander and Girdhar Gyani
}

\section{Introduction}

The health of a community is inextricably linked with the climate of the region. Climate change threatens human health by affecting the social and environmental determinants of health - clean air, safe drinking water, sufficient food and secure shelter (WHO Fact Sheet, 2018).

When climate change has an adverse effect on the health of a population, people seek healthcare services from hospitals and other healthcare providers. Hospitals themselves are known to produce significant amounts of greenhouse gas (GHG) emissions by running $24 \times 7$ on fossil fuel consumption and purchased energy sources, as well as a carbon-intensive supply chain, thereby contributing to climate change both directly and indirectly. They also generate one of the most diverse and difficult-to-manage waste streams, generated in close proximity to human beings and posing a serious threat to the safety of hospital staff, patients, their associates and the community at large. Healthcare firmly sits among the "large-emitting" sectors: in 2019, the global healthcare sector had a climate footprint of the equivalent of 2.0 gigatons of carbon dioxide $\left(\mathrm{GtCO}_{2} \mathrm{e}\right)$, equivalent to $4.4 \%$ of global net emissions (HCWH and Arup, 2019). Hence, it is crucial for hospitals and healthcare organizations to address these concerns.

The health sector is widely seen as a trusted and well-respected segment of society, as well as being a major employer in the economy. It is uniquely positioned in the community to lead by example in reducing its carbon footprint and raising awareness about climate change among the public. The sector, therefore, has both a duty and a window of opportunity to achieve climate neutrality, efficiency and cost reduction all at the same time (Neira, Bertollini et al., 2008). For this to be achieved, effective and transformative leadership is required at all levels. This chapter will look at health sector leadership in three contexts:

- The leadership of the healthcare sector in reversing global warming at a sectoral and policy level. 
- The thought leadership of healthcare institutions and providers in a community, mobilised for public advocacy to raise awareness on climate change.

- The leadership and engagement required within an individual healthcare facility to make it carbon-neutral, climate-resilient and more aware of population vulnerabilities with regard to climate change.

\section{Leadership of the health sector at the policy and sectoral level}

Globally, the voice of the healthcare sector is beginning to be heard. In a 2018 Call to Action on Climate and Health, organizations representing more than six million doctors, nurses and public health professionals and 17,000 hospitals in over 125 countries made commitments to accelerate climate change mitigation and adaptation (Global Climate and Health Forum, 2018). With its diverse supply chains and significant purchasing power, the sector has the ability to trigger climate mitigation initiatives across other sectors including plastics, chemicals, pharmaceuticals, clinical waste disposal, e-waste recycling, energy, food sourcing and preserving biodiversity.

In India, healthcare is a driving component of the economy, representing a little over $5 \%$ of the country's total expenditure (Department of Economic Affairs, Ministry of Finance, Govt. of India, 2020). The Indian healthcare sector is the fourth-largest employer in the country and runs $24 \times 7$ all year, giving it substantial economic clout. As the only sector with a duty of care as its mission, it also has significant ethical and political influence. With this size and influence in India, the healthcare sector must create the driving leadership required to slow and then reverse global warming.

The healthcare sector, already battling against the casualties of climate change on the frontlines, can lead by example in reducing its own carbon footprint. There are many examples of efficient and effective healthcare delivery with a reduced carbon footprint. If health systems across the country whole-heartedly embraced the changes required for decarbonising, the total impact of the investments would not only be massive but also rouse other sectors into realising the benefits of such an initiative. Policymakers should promote an inter-sectoral approach with the relevant government agencies to identify carbon reduction targets and set goals for GHG emissions.

Apart from reducing its own carbon footprint, strengthening its own health systems and advocating for change in climate change policy using health information, the health sector can address climate change at the policy level by collaborating with other health-determining authorities in sectors such as water, environment, agriculture and disaster management to include health in their climate adaptation plans (WHO Framework, 2017).

As a signatory to the Paris Agreement, India has committed to cut its emission intensity of GDP by 33-35\% of 2005 levels by 2030 (Aggarwal, 2015). As called for by the World Health Organization, healthcare should be integrated into climate policy, and climate policy should be integrated 
into health policy at all levels - state, national and international. In India, the government has instituted a National Expert Group on Climate Change and Human Health with experts from ministries, institutions and nongovernmental organizations. The National and State Climate Action Plans should develop a specific roadmap for the health sector. The national objectives for health, economic growth and environmental sustainability should complement each other, rather than stand as individual goals.

One way of achieving this is by using existing platforms to raise a collective voice for climate advocacy (Box 1.1). The Association of Healthcare

\section{Box 1.1 Case study}

\section{The health sector leading policy action: National Health Conclave 2019}

The Association of Healthcare Providers - India (AHPI) and the Centre for Environmental Health (CEH), a centre of excellence set up by the Public Health Foundation of India (PHFI), organised the National Health Conclave 2019, where participants deliberated on the health impacts of climate change, risk mitigation and adaptation strategies focused in the health sector (EH News Bureau, 2019). The conclave brought together health professionals, research groups, academic experts, policymakers, government officials, international agencies and civil society to deliberate on how to make the health sector climate-smart and climate-resilient, developing an agenda and roadmap for action.

The recommendations from the conclave were compiled in a white paper and presented to Dr. Harsh Vardhan, the Minister for Health and Family Welfare, Government of India, on 23 November 2019. One of the recommendations was to bring in the missing component of environmental health and associated health impacts into the medical curriculum. Subsequently, in December 2019, the National Centre of Disease Control (NCDC), an institute under the Ministry, constituted an Expert Committee on the Inclusion of Health Impacts of Climate Change in the Medical and Allied Health Curriculum. The Ministry also directed the National Board of Examinations (NBE) to implement the inclusion of health and climate change into the postgraduate medical curriculum. The NBE has already facilitated the introduction of this topic into selected postgraduate courses.

The complete white paper titled Climate Change and Health: Role of the Health Sector (AHPI and CEH, 2019) can be accessed at: https://www.ceh.org.in/publication/white-paper-on-climate-changeand-health-role-of-health-sector/ 
Providers - India (AHPI), for example, which represents the vast majority of healthcare providers in India, advocates with the government, regulatory bodies and other stakeholders on issues affecting the health sector, including climate change. The Health and Environmental Leadership Platform (HELP), of the Public Health Foundation of India (PHFI), which has over 7300 healthcare institutions (both government and private) is another platform to share best practices and showcase leadership in the adoption of climate-smart strategies.

\section{Leadership in the community}

If hospitals and healthcare centres in a community bring in clean, renewable energy and invest in conservation strategies, they become a model of leadership for the rest of the community. As major energy consumers and highly respected anchor institutions in their communities, health systems have a unique opportunity to bring about change and contribute to green local economies. By significantly ramping up investment in energy efficiency, clean energy generation and water conservation projects, health systems can initiate ideas and actions that will spread quickly into the wider economy. On seeing hospitals responding proactively to the threat of global warming, the immediate community can gain a sense of the urgency surrounding the issue.

Healthcare institutions and their employees are often considered "thought leaders" of their community. This means that any messaging around climate change that comes from health professionals contains an added value for the general public, policymakers, local leaders and media. Health sector voices can thus be used for advocacy and mass sensitisation to play a big role in policy changes. This impact must be mobilised for public advocacy to educate the general public about climate change, and in turn pressure governments to take urgent action to combat this crisis.

Health professionals need to understand how the destruction of ecosystems, decline in crop yields, and acidification of the oceans could reverse recent advances in global health, with special attention to vulnerable populations, especially those in low-income countries (Ramanathan and Haines, 2016). For all this to take place effectively, the healthcare community itself needs to be empowered through appropriate capacity-building initiatives. These initiatives should be promoted and facilitated by climate leaders from within the healthcare community (Box 1.2). During this process, it is important to involve government, academia and the private sector so that they can jointly review, identify and fill the capacity-building needs and gaps in order to achieve collective climate action.

The World Health Organization has exhorted the health community across the world to show strong leadership in tackling climate change (WHO Conference on Climate Change and Health, 2016). Healthcare providers need to be prepared on how to respond to climatic health 


\section{Box 1.2 Case study}

\section{Healthcare professionals leading change in their community: Doctors for clean air initiative}

The Lung Care Foundation, in partnership with Health Care Without Harm and Every Breath Matters, launched an initiative called Doctors for Clean Air in India, which is a collective of pulmonologists, paediatricians, cardiologists, surgeons, radiologists, etc., who are Clean Air Champions representing every state in India (HCWH Global, 2020). Having seen the alarming increase in poor health as an impact of air pollution, these medical professionals have come together to educate and advocate for better air quality in their communities. The movement describes doctors as "motivated motivators" because they see first-hand the effect of air pollution on the public, and have the ability to influence and educate their patients as they come from a position of strength.

emergencies and treat unfamiliar conditions, and sensitised in how climate change affects disease patterns and population vulnerabilities. The medical education curricula should also be modified to include climate change and its associated health impacts for healthcare students (medical, nursing, allied health and paramedical sciences).

\section{Leadership in the healthcare facility}

In any healthcare facility, effective leadership is vital for the provision and delivery of quality healthcare. The issue of leadership is even more critical for the development and maintenance of a green healthcare facility that promotes sustainability among its staff and community.

While there is no global definition or single standard of a green hospital, the ideal green hospital can be described as one that promotes public health by reducing its environmental impact and ultimately eliminating its contribution to the burden of disease. Its governance, strategy and operations all reflect the important connection between environment and human health (Karliner and Guenther, 2011). In a healthcare facility, actions and measures for carbon-neutrality and climate resilience need to be integrated into the organization's culture and placed within the context of the larger health system. This integration cannot take place without dedicated and sustained leadership and engagement.

In addition to the overarching benefit of reducing their environmental impact, leaders of healthcare facilities should consider all the other benefits of going green. The later chapters in this book describe measures and actions (in water use, waste treatment, sustainable procurement, energy use, 
indoor air quality, green housekeeping, building design, etc.) that increase operational efficiency to minimise wasteful processes and reduce GHG emissions right from the design stage. The positive impact of these measures and actions has long been established: they result in reduced staff stress and fatigue, and improved health outcomes, thereby improving patient safety (Ulrich et al., 2004). There is also a significant reduction in operational costs when hospitals practice measures to save water, electricity, gases and other consumables, eliminate unnecessary purchases, choose environmentally friendly chemicals and adopt environmentally friendly process. This brings in a financial benefit: environmentally sustainable hospitals can help to lower the cost of healthcare delivery. The leadership and top-level management of a hospital needs to be fully apprised of these benefits, which will motivate them to start implementing the measures in their facility.

Any major change initiative such as this needs the complete engagement and visible backing of the organizational leader in order to generate the desired result. Figure 1.1 lists out eight important actions that leaders must take for a successful transformation.

Climate action within a healthcare facility needs direct intervention by its leaders for two reasons: firstly, it affects the community at large as a key part of the organization's corporate social responsibility (CSR), and secondly, it impacts the hospital's bottom line. If climate action measures are categorised only as support functions, they may not be given the top priority. This is why those in charge of the healthcare facility need to lead this function from the front (Box 1.3).

A hospital leader should be adept at formulating SMART objectives, communicating through hierarchies, empowering teams, undertaking reviews and rewarding good results to keep employees motivated. Once the leadership has identified the areas of concern and developed the objectives to be achieved, the rest can be achieved by putting systems in place, and defining processes and responsibilities.

To make a healthcare facility green, a hospital leader should:

- Develop a green hospital vision and goals document laying out all the initiatives to be undertaken in each department with clearly defined roles.

- Empower the staff by conducting regular training programmes on climate change, green hospital education, organizational action and the role to be played by each employee.

- Encourage ownership by holding regular interventions such as annual and mid-term reviews, both top-down and bottom-up, to monitor and evaluate progress on the climate control vision and goals document, ensuring that standards for quality and timeliness are met.

- Adopt sustainable public procurement, which is described in detail in the chapter titled Sustainable Procurement in Healthcare. 


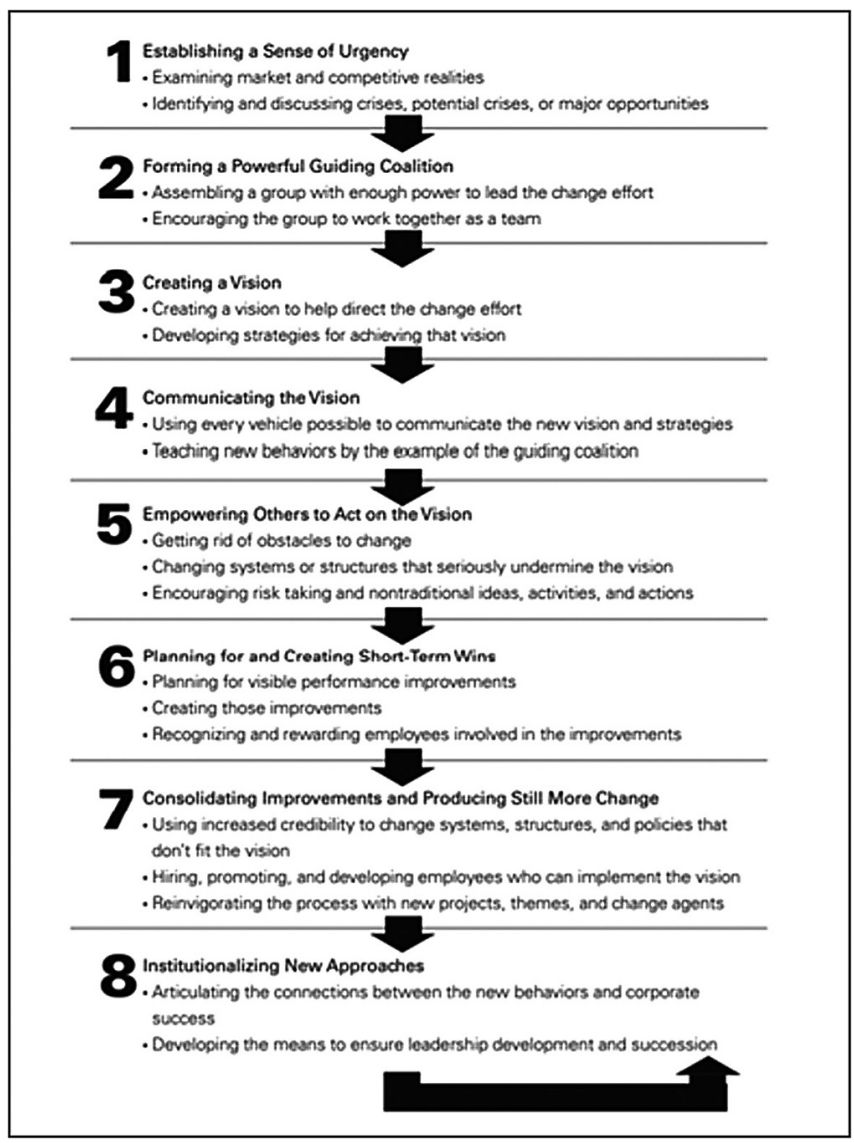

Figure 1.1 Eight steps to transforming your organization.

Source: Reprinted with permission from "Leading Change: Why Transformation Efforts Fail" by John P. Kotter. Harvard Business Review, Jan 2007. Copyright 2007 by Harvard Business Publishing; all rights reserved.

The key aspects that need to be specifically considered by hospital leaders while implementing climate action measures in their facility are summarised below:

1. Develop, document and implement a basic environment management system: identify significant aspects (such as air emissions, water discharges, chemical consumptions, etc.), set the objectives for each, and assign people to be in charge of achieving these objectives.

2. Designate a person with authority to coordinate the development and implementation of a roadmap through a shared decision-making process, so that all employees take collective ownership of the objectives. 


\section{Box 1.3 Case study}

\section{Leadership in individual health facilities: Bhagat Chandra Hospital, Dwarka, New Delhi}

The Bhagat Chandra Hospital implemented energy-saving measures right from the construction stage to make the hospital eco-friendly. In 2014, the hospital management conducted a cost-benefit analysis before exchanging all compact fluorescent lamps (CFLs) and bulbs in the hospital for light-emitting diodes (LED) lamps. The significant economic benefit of this initiative encouraged the management to introduce more lighting and solar energy initiatives to reduce the hospital's carbon footprint and invest in clean energy. In 2015, another cost-benefit analysis was done before installing $20 \mathrm{~kW}$ solar panels connected to the hospital grid, after which they saw a substantial reduction in the energy bill. In 2016, they added another $30 \mathrm{~kW}$ set of solar panels. From 2016 to 2018, the installed capacity has reduced $20-30 \%$ of the hospital's grid electricity consumption and conserved about 93,000 kilograms of $\mathrm{CO}_{2}$ emissions.

The director of the hospital and the staff of the hospital's electric department are directly involved in monitoring and evaluating the initiative. The staff who maintain the solar panels were trained by the vendor responsible for installing the solar panels. The hospital staff as a whole have been empowered to become advocates for reduced energy usage and cost savings.

Source: Global Green and Healthy Hospitals (GGHH) Case Studies, 2019.

The roadmap will be a long-term plan from which annual goals can be derived and acted upon.

3. Conduct a thorough environment assessment of the facility to identify areas and activities which are likely to have an impact on the environment: this should include relative-risk environmental impact assessment system to prioritise sustainable facility operations.

4. Define the criteria in each area of the facility, for example:

- Environment-friendly construction: this will include the selection of site for new buildings, and the evaluation and acceptance of environment-friendly material.

- Heating, Ventilation and Air-conditioning (HVAC) in the facility should protect the environment and not contaminate it in any way.

- Map the usage and conservation of water, energy and waste according to statutory norms, including actions for measurement, reduction, recycling and audits. 
5. The environment or climate control system must be integrated with the hospital's management system, including business review. If it is seen as a separate or stand-alone system, it will not deliver the desired objectives.

There have been initiatives in India to establish standards for greening health facilities. Hospitals and healthcare facilities can look to these for guidance on going green. Some of these initiatives are listed below:

- The Standard for Green and Clean Hospitals (AHPI, 2015) was established by the AHPI in 2015 and included the concepts of mitigation through resource efficiency and efficient waste management as well as measures for infection control.

- The Indian Green Building Council (IGBC) subsequently provided the IGBC Green Healthcare Facilities Rating system in 2016 which covered additional features of site selection, building material, resources and innovative design (IGBC, 2016).

- A more recent endeavour to evolve more comprehensive standards that cover all the above areas, in addition to procurement (including sustainable production and consumption), housekeeping and leadership, has been completed by the Health and Environment Leadership Platform (HELP) under the Centre for Chronic Disease Control (CCDC) and the Public Foundation of India. This will be evaluated as a complete accreditation standard for green healthcare facilities through various accreditation bodies including the National Accreditation Board for Hospitals and Healthcare Providers (NABH) and the Quality Accreditation Institute (QAI).

\section{Key takeaways}

- Climate change directly impacts the health of patients and communities. The interdependence between climate change and healthcare represents a unique opportunity for the healthcare sector to reduce climate change as well as combat it.

- The healthcare sector can be an example to other sectors by aggressively embracing climate-smart strategies, and using its collective voice for climate action at the policy level.

- The path taken by the healthcare facility affects the wellbeing of a community at large. Healthcare workers need to be sensitised about climate change and its associated impacts through the appropriate capacitybuilding interventions, so that they in turn can educate the community.

- When it comes to carbon-neutrality, going green and adopting climateresilient strategies, the leadership level of a healthcare facility needs to lead from the front. 


\section{References}

Aggarwal, M. (2015, October 3). India pledges $33-35 \%$ cut in carbon emission intensity by 2030. Livemint. https://www.livemint.com/Politics/ ZD2z2vwZktGNlzhrLujmyO/India-unveils-emission-targets-for-2030-in-UNclimate-submis.html

Association for Healthcare Providers, India. (2015). The standard for green and clean hospitals. https://www.scribd.com/document/357186023/AHPI-Standardfor-Green-Clean-Hospital

Association of Healthcare Providers India and the Centre for Environmental Health. (2019). Climate change and health: Role of the health sector [White Paper]. https://www.ceh.org.in/publication/white-paper-on-climate-changeand-health-role-of-health-sector

Department of Economic Affairs, Ministry of Finance, Govt. of India. (2020). Economic survey 2019-2020, volume II. Chapter 10: Social infrastructure, employment and human development, p. 275. https:/www.indiabudget.gov.in/ economicsurvey/doc/vol2chapter/echap10_vol2.pdf

EH News Bureau. (2019, April 1). National Health Conclave 2019 organised in Delhi.ExpressHealthcare.https:/www.expresshealthcare.in/news/national-health-conclave2019-organised-in-delhi/410386/

Global Climate and Health Forum. (2018). Call to action on climate and health. https://www.globalclimateandhealthforum.org/call-to-action

Global Green and Healthy Hospital Case Studies. (2019). A solar energy initiative to reduce cost and carbon emission: Bhagat Chandra Hospital, India. https:// www.hospitalesporlasaludambiental.net/wp-content/uploads/2018/05/SolarEnergy-Initiative-India.pdf

Healthcare Without Harm and Arup. (2019). Healthcare's climate footprint: How the bealth sector contributes to the global climate crisis and opportunities for action [Green Paper Number One], p. 4. https://noharm-global.org/sites/default/ files/documents/files/5961/HealthCaresClimateFootprint_092319.pdf

Healthcare Without Harm Global. (2020). Healthcare sector in India rises to the dual challenge of air pollution and climate change. https://noharm-global.org/ articles/news/global/health-care-sector-india-rises-dual-challenge-air-pollutionand-climate- 0

Indian Green Building Council. (2016). IGBC green healthcare facilities rating system. https://igbc.in/igbc/html_pdfs/IGBC_Green_Healthcare_Facilties.pdf

Karliner, J., \& Guenther, R. (2011). A comprehensive environmental health Agenda for hospitals and health systems around the world (p. 6). Global Green and Healthy Hospitals, HCWH. https:/www.hospitalesporlasaludambiental.net/wpcontent/uploads/2016/07/Global-Green-and-Healthy-Hospitals-Agenda.pdf

Kotter, J. P. (2007). Leading change: Why transformation efforts fail. Harvard Business Review.

Neira, M., Bertollini, R., Campbell-Lendrum, D., \& Heymann, D. L. (2008). The year 2008: A breakthrough year for health protection from climate change? American Journal of Preventive Medicine, 35(5), 424-425.

Ramanathan, V., \& Haines, A. (2016). Healthcare professionals must lead on climate change. $B M J, 355$, i5245. doi: $10.1136 /$ bmj.i5245 
Ulrich, R. S., Zimring, C., Quan, X., Joseph, A., \& Choudhary, R. (2004). The role of the physical environment in hospitals of the 21st century: A once in a lifetime opportunity. Robert Wood Johnson Foundation.

WHO Fact Sheet. (2018). Climate change and health. https://www.who.int/newsroom/fact-sheets/detail/climate-change-and-health

World Health Organization. (2016). Second global conference on bealth and climate: Conference conclusions and action agenda. https://www.who.int/globalchange/conference-actionagenda-final.pdf?ua $=1$

World Health Organization. (2017). Framework for action in building bealth systems resilience to climate change in South-East Asia Region 2017-2022, 6. https:// apps.who.int/iris/bitstream/handle/10665/258953/9789290226109-eng.pdf;jsess ionid=7FBDE165A6886DB03D51A2BEE26515AF ?sequence $=1$ 